\title{
Air Travelers' Environmental Consciousness: A Preliminary Investigation in Taiwan
}

\author{
Fang-Yuan Chen \\ Department of Transportation Technology and Management, Feng-Chia University \\ 100, Wenhwa Rd., Seatwen, Taichung 40724, Taiwan \\ E-mail: fychen@fcu.edu.tw \\ Pi-Yuan Hsu \\ Department of Transportation Technology and Management, Feng-Chia University \\ 100, Wenhwa Rd., Seatwen, Taichung 40724, Taiwan \\ E-mail: andy730hsu@gmail.com \\ Ting-Wei Lin \\ Tourism Department, Ming Chuan University \\ 5, De-Ming Rd., Gui-Shan, Taoyuan County 333, Taiwan \\ E-mail: twlin@mail.mcu.edu.tw
}

Received: June 14, 2011

Accepted: July 29, 2011 Published: December 1, 2011

doi:10.5539/ijbm.v6n12p78

URL: http://dx.doi.org/10.5539/ijbm.v6n12p78

\begin{abstract}
Today's enviornmetnal problems cannot be solved solely with technical and economic measures, a better understanding of human attitudes and behaviors is also required. This study examines air travelers' environmetnal knowledge, environmental attitudes, environmental behaviors, and pro-environmental air travel behavior in Taiwan. The relationships between environmental consciousness components with the socio-demographic variables are also tested. A field survey was administered to collect data from airline customers. The results show that Taiwanese passengers have moderate to high levels of environmetnal knowledge and overall possess a favorable environmetnal attitude. While they engage in general environmentally friendly behavior quite often, their pro-enivornmental air travel behavior is low. In addition, some differences concerning environmetnal knowledge, attitudes and behaviors exist across gender, age, and education factors. The contribution of this research is to broaden the udnerstanding of airline customers by examining their environmental consciousness and provide insights for airlines' selective marketing to enviornmentally concerned customers.
\end{abstract}

Keywords: Environmental protecion, Environmental knowledge, Environmental attitudes, Environmental behavior, Airlines

\section{Introduction}

The last two decades have witnessed a dramatic increase in environmental consciousness worldwide. Consumers are becoming increasingly concerned about environmental issues, such as climate change, ozone depletion and environmental conservation. This increase in environmental consciousness has had a profound effect on consumer demands and behaviors (Laroche et al., 2001). Specifically, consumers are demanding that corporations pay more attention to environmental conservation and protection. An increasing number of consumers state that they are ready to do more to protect the environment and are willing to choose and pay more for a product or service perceived as environmentally friendly (Ottman, 1993).

Aviation is a critical driver of global economic development. Unfortunately, aviation is also blamed for negatively impacting the natural environment through emissions, noise and waste disposal due to the industry's dynamic characteristics. According to a report by the IATA, air transport is responsible for around $2-3 \%$ of global 
man-made carbon dioxide emissions, which corresponds to $12 \%$ of the global transportation sector emissions and is expected to rise in the future (Carlsson \& Hammar, 2002). Worldwide, the aviation industry worldwide is facing increasing pressure from various stakeholders to improve its environmental performance. Airlines, as the major players of the aviation industry, are attempting to address environmental issues. For instance, a growing number of airlines have implemented Environmental Management Systems and in many cases, international environmental management standard ISO 14001 certification. Some airlines have launched carbon offset programs (e.g., Cathay Pacific's Fly Greener, KLM's CO2ZERO) which offer passengers the options of using cash or frequent flyer miles to pay for their offsets. Other measures include fleet modernization, air traffic management, aircraft maintenance, noise management, in-flight waste management, and initiatives on the ground (IATA, 2009).

In spite of these efforts, airlines rarely know how their customers view environmental issues and how they behave accordingly. It has been increasingly agreed that environmental problems cannot be solved solely with technical and economic measures, a better understanding of human attitudes and behavior should be considered as well (Abdul-Wahab, 2008). This purpose of this study is two-fold: (1) to investigate air travelers' environmental knowledge, attitudes and general behavior, as well as pro-environmental air travel behavior among Taiwanese passengers, and (2) to explore the role of socio-demographic characteristics for profiling green travelers. It is hoped that the findings can provide useful insights for both the policy makers and airline marketers in understanding their customers and fine-tuning their environmental and marketing programs.

\section{Conceptual Background}

\subsection{Environmental Consciousness}

In environmental studies, a number of different conceptualizations and instruments have been used to measure the environmental consciousness construct. To capture an adequate theoretical specification of the domains related to environmentalism, researchers have suggested that environmental consciousness should contain three components or dimensions: environmental knowledge, environmental attitudes and environmental behavior (Diamantopoulos et al., 2003; Schlegelmilch et al., 1996).

Environmental knowledge is defined as "a general knowledge of facts, concepts and relationships concerning the natural environment and its major ecosystem" (Fryxell \& Li, 2003). In order to be environmentally conscious, individuals require an understanding of the consequences of their behaviours (Bohlen et al., 1993). Schahu \& Holzer (1990) made a distinction between abstract and concrete environmental knowledge. Abstract knowledge refers to knowledge concerning environmental issues: problems, causes, solutions, and so on. Concrete knowledge relates to behavioural knowledge that could be utilized and acted upon. According to Hines et al. (1986/87), abstract knowledge is the most significant type for predicting environmental action. While some studies suggest that knowledge plays an important role in enhancing environmental attitude and behavior relationship (McFarlane \& Boxall, 2003), other studies reveal no significant or a very small relationship between knowledge and behavior (Hines 1986/87).

Environmental attitude refers to an individual's levels of concern or interest regarding aspects of environmental, ecological or energy-saving phenomena (Shrum et al., 1995). It reflects an individual's ecological worldview of humans' relationship with nature, which has been found to be an antecedent to pro-environmental behavior (Stern, 2000). Nevertheless, a number of studies have found either a moderate or a weak relationship between environmental attitudes and ecological behavior (Axelrod \& Lehman, 1993; Mostafa, 2007). The most notable scale for measuring environmental attitudes is the New Environmental Paradigm (NEP) scale developed by Dunlap \& Van Liere (1978) and later revised as the New Ecological Paradigm scale. This scale was developed to evaluate an individual's environmental orientation.

Environmental behavior can be defined by its impact or its intent. The impact-oriented definition refers to all types of behavior that change the availability of materials or energy from the environment or alter the structure and dynamics of ecosystems (Stern, 2000). The intent-oriented definition refers to behavior undertaken with the intention of changing the environment. Stern (2000) identifies four types of environmentally significant individual behaviors that may help to improve environmental quality. Among them, the personal, private-sphere environmental behavior that occurs in daily-life settings (e.g., recycling, energy conservation) could have a direct environmental consequence. Although the impact of private-sphere environmental behavior is small individually, the aggregate impact may be significant when many people choose to do so (Stern, 2000).

\subsection{The Influence of Socio-demographic Characteristics on Environmental Consciousness}

Previous research has provided much evidence of a relationship between the socio-demographic backgrounds and environmental consciousness. The most often examined socio-demographic characteristics in previous studies include gender, age, income, and education. However, the previous studies have not yet revealed a consistent result in explaining the relationship between various socio-demographic characteristics and individual 
environmental consciousness components.

For the gender variable, while some studies have found no significant relationship between gender and environmental knowledge (Diamantopoulos et al., 2003), others report that males are environmentally more knowledgeable than are females (Lyons \& Breakwell, 1994). Females have also been reported to have stronger environmental attitudes than males do (Lee, 2008; Diamantopoulos et al., 2003; Shrum et al., 1995). With regard to ecological consumer behavior, females tend to be more environmentally conscious and engage more intensively in environmentally friendly behavior than males do (Roberts, 1996; Yam-Tang \& Chan, 1998). Gender differences in environmental consciousness may stem from the early socialization process that causes females to be more concerned about other people's welfare and to assumes a greater role as caregivers (Han et al., 2011; Jain \& Kaur, 2006; Shen \& Saijo, 2008).

The relationship between age and environmental consciousness has been more consistent. The majority of previous studies report a significant and negative relationship between age and environmental knowledge, environmental attitudes and environmental behavior (Diamantopoulos et al., 2003). The study by Lee (2008) also reveals that young people are more concerned about the deterioration of environmental quality than their older counterparts. A few studies, however, report a non-significant or positive relationship between age and different environmental consciousness components (Chan, 1999; Shrum et al., 1995; Roberts, 1996).

The relationship between level of education and environmental consciousness displays more consistent results. In most studies, education level has been found to be positively related with environmental knowledge, environmental attitudes and environmental behavior (Diamantopoulos et al., 2003; Zimmer et al., 1994; Roberts, 1996). As better-educated people are more likely to have the capability to understand the complex environmental issues and problems, they may be more concerned with environmental quality and more motivated to participate in environmentally responsible behaviors (Diamantopoulos et al., 2003). A few studies, however, report an inverse relationship between education level and environmental consciousness (Samdahl \& Robertson, 1989). Based on the above literature review, the following research questions guide the analysis.

1) Do air travelers' environmental knowledge and attitudes exhibit differences across their socio-demographic characteristics?

2) Do air travelers' general environmental behaviors and pro-environmental air travel behavior exhibit differences across their socio-demographic characteristics?

\section{Methodology}

\subsection{Measures}

In the present study, environmental consciousness is defined as a multidimensional construct consisting of cognitive, attitudinal and behavioral components. The questionnaire consists of two sections. The first section contains questions about environmental knowledge, environmental attitudes, general environmental behavior and pro-environmental air travel behavior. The second section deals with questions about demographic information such as gender, age, and level of education.

The environmental knowledge scale measured the respondents' self-perception of knowledge on twelve key environmental problems covering land, air, water, land, and global environmental categories. The items were obtained from Ivy et al. (1998), Tilikidou (2007), and Abdul-Wahab (2008). Following Jain \& Kaur (2006), Cottrell (2003), and Chan (1999), respondents answered these items as true, false, or not sure (McFarlane \& Boxall, 2003). A composite knowledge score was calculated for each respondent by totaling the number of correct responses, which fell between 0 and 10. The New Environmental Paradigm (NEP) Scale was used for assessing the respondents' attitudes toward environmental issues and their concern for the environment (Dunlap \& Van Liere, 1978). This scale is composed of 12 items. For each item, respondents were asked to indicate their degree of agreement on a scale of 1 (strongly disagree) to 5 (strongly agree).

We used a 12-item scale to measure the respondents' personal, private-sphere environmental behavior that directly influences environmental quality (Stern, 2000; Straugham \& Roberts, 1999). The scale wase adapted from previous research (Tilikidou 2007; Lee, 2009; Paco \& Raposo, 2010). Respondents were asked to indicate how often they would voluntarily engage in different domains of everyday behaviors such as recycling ( 3 items), resource conservation (3 items), green purchasing ( 4 items), and transportation-related behaviors (2 items). Ratings were scored from 1 (never) to 5 (always). The mean score of the ratings of the ten items was used as the dependent variable in the analysis.

Pro-environmental behavior refers to behavior that harms the environment as little as possible, or even benefits the environment (Steg \& Vlek, 2009). Two items were used as measures of pro-environmental air travel behavior: "I choose an airline that adopts more environmentally friendly measures when I travel," and "I use cash or frequent flyer miles to buy offset for the carbon dioxide emissions of my flight". The two items tap different aspects of 
pro-environmental air travel behavior. The former indicates a general interest in choosing an environmentally friendly airline while the latter indicates a willingness to make some sacrifices to protect the environment. Ratings were also scored from 1 (never) to 5 (always). The mean score of the ratings of the two items was used as the dependent variable in the analysis.

\subsection{Data Collection and Sample Characteristics}

In the present study, a self-administered customer questionnaire survey was employed to collect data. The survey was conducted face-to-face from January to February in 2010 at the Taoyuan International Airport which is the largest airport in Taiwan. Before the formal survey, a pilot test was conducted on a sample of 30 passengers at the Taichung Airport to clarify the wording, contents and formats of the questionnaires. The results of the pilot test indicated that the items for each construct had an adequate level of reliability and validity. To increase representativeness, the formal survey was conducted over a one-week period and covered roughly all of the time intervals across the whole week. Respondents, randomly interviewed at the waiting lounges, were asked to report on statements related to environmental issues and their attitudes toward the environment.

After excluding incomplete and otherwise unusable responses, a total of 350 usable questionnaires were retrieved for analysis. The usable response rate was $60 \%$. Of the participants, 165 were male and 185 female. $53 \%$ of the respondents were between 19-29 years old and 33\% were between 30 and 49 . Among the participants, $79 \%$ had an undergraduate or postgraduate degree and $21 \%$ had less than an undergraduate college degree. Almost $35 \%$ of the respondents' monthly income was under NTD 15,000; 28\% was between NTD 30,001 and NTD 50,000. The sample mostly comprised respondents belonging to the age group 19-29, university graduates, middle-level income, and service class people.

\section{Results}

Descriptive statistics were used to summarize socio-demographic data and scores on the study variables. Independent t-tests and One-way ANOVA were carried out to assess how the respondents' environmental knowledge, environmental attitude, general environmental behavior, and pro-environment air travel behavior differed across gender, age, and education.

\subsection{Environmental Knowledge and Attitudes}

The environmental knowledge scale had a reliability alpha of 0.695 . The composite environmental knowledge score took values between 0 and 10 , which was used in the subsequent analyses. Respondents overall reported moderate to high levels of environmental knowledge (Mean $=6.845, \mathrm{SD}=2.001$ ), indicating they considered themselves somewhat knowledgeable about environmental issues or problems. Table 1 shows the environmental knowledge items and the percentages of correct as well as incorrect answers.

The environmental attitude scale had a Cronbach's areliability coefficient of 0.736 . Table 2 shows the mean for each of the environmental attitude items. The mean attitude score was 3.989 with a standard deviation of 0.475 . Only 5 items had mean scores below 4 . Generally, the respondents had a moderately positive attitude toward the environment. The respondents showed quite strong adherence to the items related to natural balance and limits to growth and were least favorable when asked about whether humans had the right to modify the natural environment.

\subsection{General Environmental Behavior and Pro-environmental Air Travel Behavior}

The respondents' general environmental behavior was measured with their recycling, resource conservation, green purchasing and transportation-related behaviors. The scale had a Cronbach's areliability coefficient of 0.756. Table 3 provides a summary of the responses to the general environmental behavior items. The mean environmental behavior score was 3.878, with a standard deviation of 0.671 . The average scores for recycling, resource conservation, green purchasing, and transportation-related behavior were: 4.268, 4.120, 3.568, and 3.629 , respectively. The results show that the respondents often acted in environmentally friendly ways. On the contrary, the mean score for pro-environmental air travel behavior was a mere 2.762 with a standard deviation of 1.194 , indicating that there was a significant gap between general environmental behavior and pro-environmental air travel behavior.

\subsection{Relationships between Environmental Knowledge, Environmental Attitude, General Environmental Behavior, Pro-Environmental Air Travel Behavior and Socio-Demographic Variables}

For the gender variable, the independent t-tests revealed that there was no significant difference in environmental knowledge, environmental attitudes and pro-environmental air travel behavior (Table 4). However, females were found to engage in more general environmental behavior than males do. The results are consistent with previous studies on gender differences in regard to environmentally friendly behaviors (Laroche et al., 2001; Roberts, 1996). 
The results of the ANOVA analyses revealed that there were significant differences in environmental knowledge and environmental attitude among education groups (Table 5). The Scheffe's post hoc test for education groups indicated that respondents having university or graduate degrees had higher environmental knowledge than those with a high school degree. Respondents with a graduate degree also had stronger environmental attitude than those with a high school degree. The results did not yield statistically significant differences in other variables.

With the exception of general environmental behavior, age had no significant difference in regard to other variables (Table 6). The Schefe post hoc analysis indicated that older people (above 50) tended to engage more in general environmental behaviors than people aged between 30 and 39. The results are contrary to those of most previous studies (Diamantopoulos et al., 2003; Lee, 2008).

\section{Conclusions and Recommendation}

\subsection{Conclusions and Discussion}

This research adds to the environmental literature by conducting a cross-cultural study on environmental consciousness in a country other than the Western world. Overall, respondents in our sample possess moderate to high levels of environmental knowledge, hold positive attitudes toward the environment and often undertake general environmental behavior. The knowledge-attitude-behavior link seems to hold in the present study. These results should not be surprising as people in Taiwan have a long history of concern for the local environment due to Taiwan's high-speed industrialization during the past several decades. The debate concerning whether economic development should take precedence over environmental protection has created much controversy in society. People acquire basic environmental knowledge and realize the severity of environmental problems through different types of mass media that play an important role in shaping public opinion. A recent example is the government's final withdrawal of support for the Kuokuang Petrochemical Project after the strong opposition from the environmentalists ${ }^{1}$.

Although a green market is still not well-defined, this study confirms, to some degree, the influence of socio-demographic variables in predicting air travelers' environmental consciousness. Some significant differences present in the environmental consciousness were found across gender, age, income, and education levels. For example, females tend to engage more intensively in environmentally friendly behavior than males do. Individuals with higher levels of education have more environmental knowledge and hold a more positive attitude toward the environment. Another interesting finding of this study, which contradicts the result of most previous studies, is that older people tend to engage in more general environmental behavior than their younger counterparts. A possible explanation is that the older generation in Taiwan has experienced serious environmental degradation resulting from rapid economic growth. They have the necessary resources and are more likely to support actual environmentally friendly behavior to protect the environment for their own health and their children's future (Diamantopoulos et al., 2003). Finally, the relatively low score of pro-environmental air travel behavior is somewhat surprising. After discussions with airline executives, we learned that Taiwanese airlines are still in the infant stage in implementing environmental management and the public has little awareness of what has been achieved. As a result, air travelers may not be able to differentiate between airlines with better environmental reputation.

\subsection{Managerial Implications}

From a management point of view, this study provides meaningful information for airline managers in Taiwan to understand their customers' environmental consciousness. First, it appears that a "general picture" of an environmentally conscious segment within the airline market may exist in Taiwan. Airlines in Taiwan should actively position their green products and services, and communicate their environmental efforts to those environmentally conscious customers in order to pursue market opportunities. Second, according to the survey results, females, older persons, and well-educated consumers are the target audience of environmental communication for Taiwanese airlines. These findings can help airline marketers recognize the characteristics of the target segments and provide valuable information for developing marketing and communication strategies (Cottrell, 2003; Chan, 1999; Roberts \& Bacon, 1997). Third, in evidence of the findings that air travelers generally have high levels of environmental consciousness, it is possible that as more travelers become aware of the availability of green alternatives, they may be more willing to make environmentally sound air travel decisions. In other words, air travelers' environmentally conscious behavior in other areas may be transferable to air travel (Birgelen et al., 2011). This further alerts Taiwanese airlines to prepare for the changes in consumer demands and behaviors from these customers.

\subsection{Limitations and Future Directions}

The first limitation concerns the social desirability effect that may bias the results. Future research should examine the potential impact of social desirability bias on the respondents' responses to survey questions. Furthermore, the measurement of pro-environmental air travel behavior may be problematic since Taiwanese 
airlines seldom promote their environmental efforts and currently no airlines have offered the carbon offset schemes in the marketplace. The development of a refined scale is needed to measure this variable. Future studies are also encouraged to use clustering technique to segment the consumers and obtain more knowledge about the target audience. In addition, the generalization of this study should be cautious since there may be country-specific factors that will affect the operationalization of the environmental consciousness construct (Diamantopoulos et al., 2003; Jain \& Kaur, 2006).

\section{Acknowledgement}

This research was financially supported by the National Science Council of Taiwan, Republic of China under Contract No. NSC 99-2410-H-035-055.

\section{References}

Abdul-Wahab, S. A. (2008). A preliminary investigation into the environmental awareness of the Omani public and their willingness to protect the environment. American Journal of Environmental Sciences, 4(1), 39-49. http://dx.doi.org/10.3844/ajessp.2008.39.49

Axelrod, L., \& Lehman, D. (1993). Responding to environmental concerns: what factors guide individual action? Journal of Environmental Psychology, 13(2), 149-159. http://dx.doi.org/10.1016/S0272-4944(05)80147-1

Birgelen, M. V., Semeijn, J., \& Behrens, P. (2011). Explaining pro-environment consumer behavior in air travel. Journal of Air Transport Management, 17(2), 125-128. http://dx.doi.org/10.1016/j.jairtraman.2010.12.013

Bohlen, G. M., Schlegelmilch, B. B., \& Diamantopoulos, B. B. (1993). Measuring ecological concern: a multi-construct perspective. Journal of Markeing Management, 9(4), 415-430. http://dx.doi.org/10.1080/0267257X.1993.9964250

Carlsson, F., \& Hammar, H. (2002). Incentive-based regulation of $\mathrm{CO}_{2}$ emissions from international aviation. Journal of Air Transport Management, 8(6), 365-372. http://dx.doi.org/10.1016/S0969-6997(02)00011-X

Chan, K. (1999). Market segmentation of green consumers in Hong Kong. Journal of International Consumer Marketing, 12(2), 7-24. http://dx.doi.org/10.1300/J046v12n02_02

Cottrell, S. P. (2003). Influence of sociodemographics and environmental attitudes on general responsible environmental behavior among recreational boaters. Environment and Behavior, 35(3), 347-375. http://dx.doi.org/10.1177/0013916503035003003

Diamantopoulos, A., Schlegelmilch, B. B., Sinkovics, R. R., \& Bohlen, G. M. (2003). Can socio-demographics still play a role in profiling green consumers? A review of the evidence and an empirical investigation. Journal of Business Reserch, 56(6), 465-480. http://dx.doi.org/10.1016/S0148-2963(01)00241-7

Dunlap, R. E., \& Van Liere, K. D. (1978). The New Environmental Paradigm: a proposed measureing instrument and preliminary results. Journal of Environmental Education, 9(4), 10-19.

Fryxell, G., \& Lo, C. (2003). The influence of environmental knowledge and values on managerial behaviors on behalf of the environment: an empirical examination of managers in China. Journal of Business Ethics, 46(1), 45-59. http://dx.doi.org/10.1023/A:1024773012398

Han, H., Hsu, L. T. J., Lee, J. S., \& Sheu, C. (2011). Are lodging customers ready to go green? An examination of attitudes, demographics, and eco-friendly intentions. International Journal of Hospitality Management, 30(2), 345-355. http://dx.doi.org/10.1016/j.ijhm.2010.07.008

Hines, J. M., Hungerford, H. R., \& Tomera, A. N. (1986/87). An analysis and synthesis of research on responsible envrionmental behavior: A meta-analysis. Journal of Environmental Education, 18(2), 1-8. http://dx.doi.org/10.1080/00958964.1987.9943482

IATA annual report. (2009). International Air Transport Assocation.

Ivy, T. G. C., Lee, C. K. E., \& Chuan, G. K. (1998). A survey of environmental knowledge, attitudes and behaviour of students in Singapore. International Research in Geographical and Environmental Education, 7(3), 181-202. http://dx.doi.org/10.1080/10382049808667574

Jain, S. K., \& Kaur, G. (2006). Role of socio-demographics in segmenting and profiling green consumers: an exploratory study of consumers in India. Journal of International Consumer Marketing, 18(3), 107-146. http://dx.doi.org/10.1300/J046v18n03_06

Laroche, M, Bergeron, J., \& Forleo, G. B. (2001). Targeting consumers for environmentally friendly products. Journal of Consumer Marketing, 18(6), 503-520. http://dx.doi.org/10.1108/EUM0000000006155

Lee, K. (2008). Making environmental communications meaningful for female adolescents - a study in Hong Kong. Science Communication, 30(2), 147-176. http://dx.doi.org/10.1177/1075547008324364 
Lee, K. (2009). Gender differences in Hong Kong adolescent consumers' green purchasing behavior. Journal of Consumer Marketing, 26(2), 87-96. http://dx.doi.org/10.1108/07363760910940456

Lyons, E., \& Breakwell, G. M. (1994). Factors predicting environmental concern and indifference in 13-16-year-olds. Environment and Behavior, 26(2), 223-238. http://dx.doi.org/10.1177/001391659402600205

McFarlane, B. L., \& Boxall, P. C. (2003). The role of social psychological and social structural variables in environmental activism: an example of the forest sector. Journal of Environmental Psychology, 23(1), 74-87. http://dx.doi.org/10.1016/S0272-4944(02)00080-4

Mostafa, M. M. (2007). Gender differences in Egyptian consumers' geen purchase behaviour: the effects of environmental knowledge, concern and attitude. International Journal of Consumer Studies, 31(3), 220-229. http://dx.doi.org/10.1111/j.1470-6431.2006.00523.x

Ottman, J. A. (1993). Green Marketing: Challenges and Opportunities. NTC Business Books, Chicago, IL.

Paco, A. M. F., \& Raposo, M. L. B. (2010). Green consumer market segmentation: empirical findings from Portugal. International Journal of Consumer Studies, 34(4), 420-436.

Roberts, J. A. (1996). Green consumers in the 1990s: profile and implications for advertising. Journal of Business Research, 36(3), 217-231. http://dx.doi.org/10.1016/0148-2963(95)00150-6

Roberts, J. A., \& Bacon, D. R. (1997). Exploring the subtle relationshps between environmetnal concern and ecologically conscious consumer behavior. Journal of Business Research, 40(1), 79-89. http://dx.doi.org/10.1016/S0148-2963(96)00280-9

Samdahl, D. M., \& Robertson, R. (1989). Social determinants of environmental concern: specification and test of the model. Environment and Behavior, 21(1), 57-81. http://dx.doi.org/10.1177/0013916589211004

Schahu, J., \& Holzer, E. (1990). Studies of individual environmental concern: the role of knowledge, gender and background varialbe. Environment and Behavior, 22(6), 767-786. http://dx.doi.org/10.1177/0013916590226003

Schlegelmilch, B., B., Bohlen, G. M., \& Diamantopoulos, A. (1996). The link between green purchasing decisions and measures of environmental consciousness. European Journal of Marketing, 30(5), 35-55. http://dx.doi.org/10.1108/03090569610118740

Shen, J., \& Saijo, T. (2008). Reexamining the relations between socio-demographic characteristics and inidvidual environmental concern: evidence from Shanghai data. Journal of Environmental Psychology, 28(1), 42-50. http://dx.doi.org/10.1016/j.jenvp.2007.10.003

Shrum, L. J., McCarty, J. A., \& Lowrey, T. M. (1995). Buyer characteristics of the green consumer and their implications for advertising strategy. Journal of Advertising, 24(2), 71-82.

Steg, L., \& Vlek, C. (2009). Encouraging pro-environmental behaviour: an integrative review and research agenda. Journal of Environmnetal Psychology, 29(3), 309-317. http://dx.doi.org/10.1016/j.jenvp.2008.10.004

Stern, P. C. (2000). Toward a coherent theory of environmentally significant behavior. Journal of Social Issues, 56(3), 407-424. http://dx.doi.org/10.1111/0022-4537.00175

Straughan, R. D., \& Roberts, J. A. (1999). Environmental segmentation alternatives: a look at green consumer behavior in the new millennium. Journal of Consumer Marketing, 16(6), 558-575. http://dx.doi.org/10.1108/07363769910297506

Tilikidou, I. (2007). The effects of knowledge and attitudes upon Greeks' pro-environmental purchasing behaviour. Corporate Cocial Responsibility and Environmental Management, 14(3), 121-134. http://dx.doi.org/10.1002/csr.123

Yam-Tang, E. P. Y., \& Chan, R. Y. K. (1998). Purchasing behaviors and perceptions of environmental harmful products. Marketing Intelligence and Planning, 16(6), 365-362. http://dx.doi.org/10.1108/02634509810237532

Zimmer, M. R., Stafford, T. F., \& Stafford, M. R. (1994). Green issues dimensions of environmental concern. Journal of Business Research, 30(1), 63-74. http://dx.doi.org/10.1016/0148-2963(94)90069-8

\section{Note}

Note 1. The Kuokuang petrochemical project was initiated by the state-run refinery Chinese Petroleum Corporation, Taiwan to relocate its crude refining plants in southern Taiwan's Kaohsiung City to Changhua County by 2015 , where it plans to invest US $\$ 12.57$ billion to construct the petrochemical complex. 
Table 1. Environmental Knowledge Questions

\begin{tabular}{|l|c|c|}
\hline \multicolumn{1}{|c|}{ Scale items } & $\begin{array}{c}\text { Correct } \\
(\%)\end{array}$ & $\begin{array}{c}\text { Incorrect } \\
(\%)\end{array}$ \\
\hline Motor vehicles and industries are the primary sources of air pollution in cities. (true) & 75.8 & 24.2 \\
Air transport contributes 20\% of global man-made CO2 emissions. (false) & 40.8 & 59.2 \\
Carbon dioxide $\left(\mathrm{CO}_{2}\right)$, methane $\left(\mathrm{CH}_{4}\right.$ ) and water vapor are some examples of & 51.6 & 48.4 \\
greenhouse gases. (true) & & \\
Dumping of waste by factories is the major cause of water pollution. & 78.5 & 21.5 \\
Coral reefs and rain forests are the places with high biodiversity. (true) & 73.4 & 26.6 \\
Increased amount of carbon dioxide in the atmosphere which traps the heat radiated & 65.3 & 34.7 \\
from the ground is the cause of the greenhouse effect. (true) & & \\
Global warming is an international environmental problem. (true) & 90.8 & 9.2 \\
Using disposable paper cups is much better than washing mugs after each use. & 82.6 & 17.4 \\
(false) & 42.9 & 57.1 \\
Less than 1\% of the world's water is available for human use. (true) & 68.7 & 31.3 \\
Ozone protects us from harmful, cancer-causing sunlight. (true) & 85.3 & 14.7 \\
Oil is a renewable resource. (false) & 82.1 & 17.9 \\
Loss of habitat is the most common reason that animal species become extinct. & & \\
(true) & & \\
\hline
\end{tabular}

* 1. Correct answer is shown in parenthesis. 2. Not sure answers included in "incorrect" portion.

Table 2. Scores on Environmental Attitudes

\begin{tabular}{|l|c|c|}
\hline \multicolumn{1}{|c|}{ Scale items } & Mean & SD \\
\hline The balance of nature is very delicate and easily upset & 4.148 & 0.765 \\
When humans interfere with nature, it often produces disastrous consequences & 4.420 & 0.654 \\
Humans must live in harmony with nature in order to survive & 4.531 & 0.625 \\
Humans are severely abusing the environment & 4.514 & 0.571 \\
We are approaching the limit of the number of people the earth can support & 4.036 & 0.822 \\
The earth is like a spaceship with only limited room and resources & 4.328 & 0.633 \\
There are limits to growth beyond which our industrialized society can't expand & 4.003 & 0.808 \\
To maintain a health economy, we will help to develop a steady-state economy & 3.987 & 0.855 \\
where industrial growth is controlled & & \\
Humans have the right to modify the natural environment to suit their needs (R) & 2.645 & 1.264 \\
Humans were meant to rule over the rest of the world (R) & 3.525 & 1.326 \\
Plants and animals exist primarily to be used by humans (R) & 3.829 & 1.195 \\
Humans need not adapt to the natural environment because they can remake it to & 3.921 & 1.164 \\
remake it to suit their needs (R) & & \\
\hline Overall mean & $\mathbf{3 . 9 8 9}$ & $\mathbf{0 . 4 7 5}$ \\
\hline
\end{tabular}

* $\mathrm{R}$ means item reverse-coded prior to further analysis.

Table 3. Scores on General Environmental Behavior

\begin{tabular}{|l|c|c|}
\hline \multicolumn{1}{|c|}{ Scale items } & Mean & SD \\
\hline I make every effort to buy paper products made from recycled paper. & 4.016 & 0.891 \\
I try only to buy products that can be recycled. & 3.678 & 0.695 \\
I recycle paper, glass, plastic and metal waste products. & 4.351 & 0.517 \\
I try to reduce the amount of water I use. & 4.252 & 0.486 \\
I try very hard to reduce the amount of electricity I use. & 4.487 & 0.744 \\
I try to reduce overall consumption. & 3.725 & 0.683 \\
I will not buy products which have excessive packaging. & 3.506 & 0.877 \\
I always choose the product that causes less harm to the environment. & 3.606 & 0.678 \\
Whenever possible, I buy products in reusable containers. & 3.454 & 0.746 \\
I have switched products for ecological reasons. & 3.515 & 0.951 \\
I use public transportation to go to work whenever possible. & 3.989 & 0.510 \\
To reduce our reliance on fossil oil, I drive my car as little as possible. & 4.024 & 0.497 \\
\hline Overall mean & $\mathbf{3 . 8 7 8}$ & $\mathbf{0 . 6 7 1}$ \\
\hline
\end{tabular}


Table 4. Independent t-test Results by Gender

\begin{tabular}{|l|l|c|c|c|}
\hline \multicolumn{1}{|c|}{ Variables } & Gender & Mean (SD) & t-value & p-value \\
\hline Environmental knowledge & Male & $7.065(1.994)$ & -1.465 & 0.144 \\
& Female & $6.672(2.000)$ & & \\
\hline Environmental attitude & Male & $3.989(0.479)$ & 0.001 & 0.999 \\
& Female & $3.989(0.473)$ & & \\
\hline General environmental behavior & Male & $3.740(0.714)$ & 2.729 & 0.007 \\
& Female & $3.984(0.618)$ & & \\
\hline Pro-environmental air travel behavior & Male & $2.768(1.205)$ & 0.063 & 0.950 \\
& Female & $2.758(4.141)$ & & \\
\hline
\end{tabular}

Table 5. One-way ANOVA Results by Education

\begin{tabular}{|l|l|r|r|r|l|}
\hline \multicolumn{1}{|c|}{ Variables } & \multicolumn{1}{|c|}{ Education } & Mean (SD) & F-value & p-value & Scheffe \\
\hline Environmental knowledge & High school or less (1) & $5.456(2.329)$ & 16.440 & 0.000 & $(2)>(1)$ \\
& University (2) & $7.233(1.676)$ & & & $(3)>(1)$ \\
& Graduate (3) & $7.108(2.024)$ & & & \\
\hline Environmental attitude & High school or less (1) & $3.795(0.494)$ & 5.017 & 0.007 & $(2)>(1)$ \\
& University (2) & $4.043(0.453)$ & & & \\
& Graduate (3) & $4.023(0.489)$ & & & \\
\hline General environmental & High school or less (1) & $3.860(0.789)$ & 0.171 & 0.843 & \\
behavior & University (2) & $3.895(0.657)$ & & & \\
& Graduate (3) & $3.821(0.541)$ & & & \\
\hline Pro-environmental air travel & High school or less (1) & $2.777(1.136)$ & 3.330 & 0.038 & $(2)>(3)$ \\
behavior & & & & & \\
& University (2) & $2.861(1.199)$ & & & \\
& Graduate (3) & $2.241(1.162)$ & & & \\
\hline
\end{tabular}

Table 6. One-way ANOVA Results by Age

\begin{tabular}{|l|l|l|l|l|l|}
\hline \multicolumn{1}{|c|}{ Variables } & \multicolumn{1}{|c|}{ Age } & Mean (SD) & F-value & p-value & Scheffe \\
\hline Environmental knowledge & Under 29 (1) & $6.752(1.920)$ & 0.195 & 0.900 & \\
& $30-39(2)$ & $7.004(1.874)$ & & & \\
& $40-49(3)$ & $6.957(1.874)$ & & & \\
& Above 50 (4) & $6.849(2.002)$ & & & \\
\hline Environmental attitude & Under 29(1) & $4.021(0.471)$ & 1.894 & 0.131 & \\
& $30-39(2)$ & $3.943(0.484)$ & & & \\
& $40-49(3)$ & $4.055(0.463)$ & & & \\
& Above 50 (4) & $3.800(0.467)$ & & & \\
\hline General environmental behavior & Under 29(1) & $3.843(0.692)$ & 3.480 & 0.017 & $(4)>(2)$ \\
& $30-39(2)$ & $3.711(0.597)$ & & & \\
& $40-49(3)$ & $3.918(0.645)$ & & & \\
\hline Pro-environmental air travel & Above 50(4) & $4.240(0 . .614)$ & & & $(4)>(2)$ \\
behavior & Under 29(1) & $2.736(1.131)$ & 2.886 & 0.037 & \\
& & & & & \\
& $30-39(2)$ & $2.434(1.181)$ & & & \\
& $40-49(3)$ & $2.808(1.249)$ & & & \\
& Above 50 (4) & $3.320(1.290)$ & & & \\
\hline
\end{tabular}

